\title{
PERENCANAAN SISTEM DISTRIBUSI AIR BERSIH DI DESA TAMBAKRIGADUNG KECAMATAN TIKUNG KABUPATEN LAMONGAN
}

\author{
Erick Budhi Afryono ${ }^{1)}$, Nur Azizah Afandy ${ }^{2)}$ \\ ${ }^{1)}$ Program Studi Teknik Sipil Fakultas Teknik Universitas Islam Lamongan \\ ${ }^{2)}$ Program Studi Teknik Sipil Fakultas Teknik Universitas Islam Lamongan \\ Email : wakric59@gmail.com, Nurazizah_5@gmail.com
}

\begin{abstract}
Abstrak
Air bersih merupakan salah satu kebutuhan dasar manusia dan merupakan kebutuhan mutlak yang harus dipenuhi untuk segala kebutuhan sehari-hari. Demikian pula yang dirasakan oleh masyarakat di Desa Tambakrigadung. Saat ini Desa Tambakrigadung dalam pemenuhan Airnya menggunakan sumur, dan sebagian warga ada pula yang menggunakan Air dari weslik setempat. Maka memerlukan adanya air yang lebih layak untuk memenuhi kebutuhan sehari-hari. Salah satu alternative adalah dengan mendapatkan air bersih dari PDAM Lamongan mengingat PDAM Lamongan saat ini, melayani Desa Tambakrigadung dimana jarak perpipahanya tidak jauh dari Desa Tambakrigadung yaitu \pm 500 meter. Untuk itu perlu di analisa apakah PDAM Lamongan mampu melayani kebutuhan Desa Tambakrigadung dengan cara menghitung kebutuhan air Desa tambakrigadung dan membuat suatu analisa jaringan perpipaan yang diambilkan (Tapping) dari pipa utama PDAM yang menuju perumahan Graha Indah Lamongan. Dalam pelaksanaannya, sistem penyediaanya air bersih di Desa Tambakrigadung belum dapat berjalan dengan lancar. Berdasarkan hasil perhitungan kebutuhan air dan ketersediaan air yang ada adalah 30 lt/dtk, dan yang dibutuhkan Desa Tambakrigadung 10 1/dtk berarti sumber air tersebut lebih dari cukup untuk memenuhi kebutuhan air pada 5 tahun kedepan dengan pelayanan $80 \%$
\end{abstract}

Kata Kunci : Air Bersih, Resevoir, Pompa, Node

\begin{abstract}
Clean water is one of the basic human needs and is an absolute necessity that must be met for everyday needs. Similarly, felt by the community in Tambakrigadung Village. Currently Tambakrigadung Village in the fulfillment of its water use wells, and some residents also use water from local weslik. Then require the existence of water more feasible to meet daily needs. One alternative is to get clean water from Lamongan PDAM considering Lamongan PDAM at present, serving Desa Tambakrigadung where the distance of the pipeline is not far from Tambakrigadung Village which is \pm 500 meter. It is therefore necessary to analyze whether Lamongan PDAM is able to serve the needs of Tambakrigadung Village by calculating the water needs of tambakrigadung village and making a pipeline network analysis taken (Tapping) from PDAM main pipeline towards Graha Indah Lamongan housing. In its implementation, the clean water supply system in Tambakrigadung village has not been able to run smoothly. Based on the calculation of water demand and available water availability is $30 \mathrm{lt} / \mathrm{sec}$, and the required Tambakrigadung Village $101 / \mathrm{s}$ means the water source is more than enough to meet the water needs in the next 5 years with service $80 \%$.
\end{abstract}

Keywords: Water Supply, Resevoir, Pump, Node 


\section{PENDAHULUAN}

Desa Tambakrigadung merupakan air yang tidak layak dijadikan air bersih dikarenakan air diwilayah tersebut tidak jernih, melainkan keruh, air berwarna kuning/merah kecoklatan. Maka memerlukan adanya air yang lebih layak untuk memenuhi kebutuhan seharihari. Salah satu alternative adalah dengan mendapatkan air bersih dari PDAM Lamongan mengingat PDAM lamongan saat ini, melayani Desa Tambakrigadung dimana jarak perpipahanya tidak jauh dari Desa Tambakrigadung yaitu \pm 500 meter. Untuk itu perlu di analisa apakah PDAM Lamongan mampu melayani kebutuhan Desa Tambakrigadung dengan cara menghitung kebutuhan air Desa tambakrigadung dan membuat suatu analisa jaringan perpipaan yang diambilkan (Tapping) dari pipa utama PDAM yang menuju perumahan Graha Indah Lamongan.

Untuk itu perlu di analisa apakah PDAM Lamongan mampu melayani kebutuhan Desa Tambakrigadung dengan cara menghitung kebutuhan air Desa tambakrigadung dan membuat suatu analisa jaringan perpipaan yang diambilkan (Tapping) dari pipa utama PDAM yang menuju perumahan Graha Indah Lamongan

PDAM Lamongan sebagai salah satu instansi terkait tidak lepas dari usaha peningkatan pelayanan kepada masyarakat. Untuk usaha tersebut PDAM Lamongan merencanakan sistem distribusi yang harus sesuai dengan debit air yang ada. PDAM sudah memasok air bersih, antara lain ke Perumahan Graha Indah yang termasuk memasuki wilayah Kecamatan Tikung Lamongan

\section{METODELOGI PENELITIAN}

\section{Proyeksi Penduduk Pada Daerah Pelayanan}

Dalam perencanaan dan menghitung jumlah penduduk pada akhir umur rencana,mempergunakan pertambahan jumlah penduduk dan prosentase pertambahan penduduk pada Desa Tambakrigadung.

\section{Proyeksi Jumlah Kebutuhan Air}

Distribusi air dari sumber air (reservoir) yang mempunyai debit relatif konstan, melalui jalur pipa dengan waktu pengaliran selama 24 jam atau terus menerus agar distribusi tetap berjalan dengan baik, maka faktor terpenting yang harus diperhatikan adalah besarnya kapasitas air bersih yang didistribusikan. Untuk merencanakan sebuah pusat air minum, terlebih dahulu harus ditentukan daerah dan jumlah penduduk yang dilayani. Kemudian jumlah air yang harus disediakan serta jumlah air baku yang harus disadap dari sumber air juga harus ditentukan. Dalam perencanaan jumlah penyediaan air, perlu diperkirakan keperluan per kapita per hari, jika angka ini dikalikan dengan jumlah penduduk yang akan dilayani, maka akan dapat diperoleh jumlah air yang diperlukan per hari.

Untuk menentukan kapasitas aliran yang diperlukan harus diperkirakan pula ratarata dalam kondisi puncak (maksimum) per jam yang terjadi dalam satu waktu. Selanjutmya untuk memperkirakan pengembangan instalasi di masa mendatang, perlu didasari dari catatan dan pengalaman yang pernah dilakukan.

\section{Jaringan Pipa Induk Distribusi}

Diameter pipa distribusi utama adalah $450 \mathrm{~mm}, 300 \mathrm{~mm}$ dan $250 \mathrm{~mm}$ terbuat dari bahan besi baja, sedangkan pipa diameter lebih kecil dari $250 \mathrm{~mm}$ terbuat dari PVC. Jaringan pipa ini juga harus bisa mengetahui pipa distribusi utama yang sudah terpasang diwilayah Desa Tambakrigadung.

Volume reservoir yang sebenarnya adalah seluruh sistem tampungan yang ada dalam jaringan berupa reservoir itu sendiri. Dalama evaluasi ini debit yang dibutuhkan sbesar 243,48 1t/detik pada kondisi pemakaian puncak. Setelah itu air yang masuk ke reservoir untuk didistribusikan ke seluruh wilayah pelayanan khususnya wilayah Dusun Tambak Boyo.

\section{Pengolahan dan Analisa Data}

Untuk menentukan jumlah kebutuhan air bersih pada suatu daerah dalam tahun atau priode tertentu, maka hal ini perlu diperhatikan adalah jumlah penduduk pada tahun rencana tersebut harus diketahui. Ada tiga metode untuk proyeksi penduduk: metode aritmatik, metode geometrik dan metode least squere. Pada perencanaan ini, untuk memproyeksikan jumlah penduduk pada tahun rencana tersebut digunakan rumus metode geometrik (Bunga berganda)(Farhat yusuf)

Pada perencanaan ini, untuk memproyeksikan jumlah penduduk pada tahun 
rencana tersebut digunakan rumus metode

geometrik (Bunga berganda).

Afryono / Perencanaan Sistem Distribusi Air Bersih Di Desa Tambakrigadung Kecamatan Tikung Kabupaten Lamongan /JT, Vol 9 No.1, Maret 2017, pp 49 - 56

Tabel 1. Jumlah Penduduk di Dusun

Tambakboyo

\begin{tabular}{lllllll}
\hline \multirow{2}{*}{ No } & \multirow{2}{*}{ Dusun } & \multicolumn{5}{c}{ Tahun } \\
\cline { 3 - 7 } & & 2008 & $\mathbf{2 0 0 9}$ & $\mathbf{2 0 1 0}$ & $\mathbf{2 0 1 1}$ & $\mathbf{2 0 1 2}$ \\
\hline 1 & Tambakboyo & 5386 & 5449 & 5487 & 5543 & 5598 \\
\hline \multicolumn{2}{c}{ Jumlah } & 5386 & 5449 & 5487 & 5543 & 5598 \\
\hline \multicolumn{2}{c}{ Sumber: hasil sensus penduduk tahun } & 2012 \\
\end{tabular}

Tabel 2. Prosentase Perkembangan

Penduduk Dusun Tambakboyo Tahun 2008-

2012

\begin{tabular}{llll}
\hline No & Tahun & Pertambahan & $\begin{array}{l}\text { Prosentase } \\
\%\end{array}$ \\
\hline 1 & $2008-2009$ & 63 & 1.1 \\
\hline 2 & $2009-2010$ & 38 & 0.6 \\
\hline 3 & $2010-2011$ & 56 & 1 \\
\hline 4 & $2011-2012$ & 55 & 0.9 \\
\hline & Rata-rata & 40 & 0.9
\end{tabular}

Sumber: hasil sensus penduduk tahun 2012

Untuk mencari rata-rata:

$$
\begin{aligned}
\mathrm{R} & =\frac{1,1+0.6+1+0.9+1.1}{5} \\
& =0,9 \%
\end{aligned}
$$

Contoh Perhitungan untuk mencari jumlah penduduk pada tahun 2013

$$
\begin{aligned}
& \mathrm{Pt}=\mathrm{p}_{\mathrm{o}}(1+\mathrm{r})^{\mathrm{t}} \\
& =5598(1+0,9 \%)^{1}=5648 \text { jiwa }
\end{aligned}
$$

\section{Analisa Kebutuhan Air Bersih}

Analisa Jumlah sambungan rumah

Untuk merencanakan jumlah sambungan rumah, pada perencanaan kebutuhan air bersih ini dalam satu rumah diasumsikan dihuni oleh 5 jiwa.

Jumlah sambungan rumah

$$
\begin{aligned}
& =\frac{\text { jumlah penduduk } x \text { target pelayanan }}{5} \\
& =\frac{6907 \times 80 \%}{5}=1105 \mathrm{SR}
\end{aligned}
$$

\section{Analisa Jumlah (HU) Hidran Umum}

Pada perencanaan ini hidran umum diasumsikan dimanfaatkan oleh 100 jiwa, dan untuk menentukan jumlah hidran umum adalah sebagai berikut:

$$
\text { Jumlah HU = }
$$

$$
\begin{aligned}
& =\frac{6907 \times 80 \%}{100} \\
& =55 \text { unit }
\end{aligned}
$$

Analisa Kebutuhan Air Domestik

Untuk merencanakan kebutuhan air domestik ini diasumsikan kebutuhan air bersih setiap orang 1601t/jiwa/hari, dan prosentase target pelayanan $80 \%$ dari jumlah penduduk pada tahun rencana secara keseluruhan, dimana jumlah penduduk pada tahun rencana tersebut yaitu tahun 2018 sebesar 6097 jiwa.

Maka perkiraan kebutuhan air domestik untuk 2018 adalah:

Kebutuhan air domestik $=$ (jumlah penduduk x $80 \%$ )x $1601 \mathrm{t} / \mathrm{jw} / \mathrm{hr}$

$$
=(6907 \times 80 \%) \times
$$

$$
=10 \mathrm{lt} / \mathrm{dt}
$$

\section{Analisa Kehilangan Air}

Untuk menghitung analisa kehilangan air, diproyeksikan sebesar 20$30 \%$ dari jumlah kebutuhan air domestik. Sedangkan analisa kehilangan air pada perencanaan ini diasumsikan sebesar $20 \%$ dari kebutuhan domestik dan kebutuhan non domestik.

(Linsley,teknik sumber daya air)

Maka perkiraan kemungkinan kehilangan air bersih pada tahun 2018 adalah:

Kehilangan air $=20 \% \quad($ kebutuhan domestik)

$$
\begin{aligned}
& =20 \%(10 \mathrm{lt} / \mathrm{dt}) \\
& =2 \mathrm{lt} / \mathrm{dt}
\end{aligned}
$$

\section{Analisa Konsumsi Harian Komulatif}

Untuk menghitung kebutuhan komulatif dihitung berdasarkan penjumlahan dari kebutuhan air domestik, kebutuhan air non domestik, kebutuhan air non domestik dan kehilangan air.

Sehingga kebutuhan air komulatif pada tahun 2018 adalah:

Konsumsi harian komulatif

$$
\begin{aligned}
& =10+2 \\
& =12 \mathrm{lt} / \mathrm{dt} .
\end{aligned}
$$

\section{Analisa Kebutuhan Air Harian}


Setelah diketahui jumlah kebutuhan air bersih maksimum perorang, maka untuk menghitung jumlah kebutuhan air harian maksimum adalah:

$$
\begin{aligned}
& =1,2 \times \text { kebutuhan rata-rata } \\
= & 1,2 \times 12 \\
= & 13,2 \mathrm{lt} / \mathrm{dt}
\end{aligned}
$$

\section{Analisa kebutuhan Jam Puncak}

Afryono / Perencanaan Sistem Distribusi Air Bersih Di Desa Tambakrigadung Kecamatan Tikung Kabupaten Lamongan /JT,Vol 9 No.1, Maret 2017, pp 49-56

Dari perhitungan analisa kebutuhan air maksimum, maka dapat diketahui kebutuhan air jam puncak untuk tahun rencana yaitu tahun 2018, untuk menentukan analisa kebutuhan jam puncak dapat dicari dengan jumlah kebutuhan air maksimum dikali faktor kebutuhan jam puncak. Faktor kebutuhan jam puncak diambil 1,5 $\mathrm{x}$ kebutuhan harian maksimum. Sularso,Haruo.T Pompa dan kompresor)

Sehingga kebutuhan air jam puncak taahun 2018 adalah:

Kebutuhan air jam puncak: $=1,5 \mathrm{x}$ kebutuhan harian maksimum

\begin{tabular}{|c|c|c|c|c|c|c|}
\hline \multirow[t]{2}{*}{ No } & \multirow[t]{2}{*}{ Keterangan } & \multirow[t]{2}{*}{ Satuan } & \multicolumn{4}{|c|}{ Tahun } \\
\hline & & & 2013 & 2014 & 2016 & 2018 \\
\hline 1. & Jumlah penduduk & Jiwa & 5648 & 5699 & 5962 & 6907 \\
\hline 2. & Cakupan pelayanan & $(\%)$ & 80 & 80 & 80 & 80 \\
\hline 3. & Kebutuhan air & jiwa & 903 & 911 & 928 & 1105 \\
\hline 4. & Domestik & $\mathrm{Lt} / \mathrm{dt}$ & 8,3 & 8,4 & 8,6 & 10 \\
\hline 5 & $\begin{array}{l}\text { Kehilangan air (kebutuhan) } 20 \% \\
\text { Kebutuhan rata-rata }\end{array}$ & $\mathrm{Lt} / \mathrm{dt}$ & 1,66 & 1,68 & 1,72 & 2 \\
\hline 6 & Kebutuhan harian maksimum (kebutuhan & $\mathrm{Lt} / \mathrm{dt}$ & 9,96 & 10,08 & 10,12 & 12 \\
\hline 7 & rata-rata $\times 1,2)$ & $\mathrm{Lt} / \mathrm{dt}$ & 11,95 & 12 & 12,14 & 13,2 \\
\hline 8 & $\begin{array}{l}\text { Kebutuhan jam puncak (kebutuhan } \\
\text { maksimum x 1,5) }\end{array}$ & $\mathrm{Lt} / \mathrm{dt}$ & 17,9 & 18 & 18,21 & 20 \\
\hline
\end{tabular}

$$
\begin{aligned}
& =1,5 \times 13,2 \\
& =19,8 \mathrm{lt} / \mathrm{dt}=20 \mathrm{lt} / \mathrm{dt}
\end{aligned}
$$

Tabel 3. kriteria sistem pelayanan air bersih Dusun Tambakboyo

Sumber: hasil perhitungan

Keterangan:

- Cakupan layanan lima tahun pertama 80\% (BAPPENAS)

- Cakupan layanan untuk lima tahun berikutnya $90 \%$ (BAPPENAS)

- Pada tahun rencana untuk sambungan langsung 160 lt/orang/hari

- $\quad$ Sedang untuk hidran umum 80 lt/orang/hari

Hasil perhitungan selanjutnya dapat dilihat pada tabel dibawah ini:

Tabel 4. Prosentase Perkembangan Penduduk Dusun Tambakboyo Tahun 2006-2012

\begin{tabular}{lll}
\hline No & Tahun & $\begin{array}{l}\text { Jumlah penduduk } \\
\text { (jiwa) }\end{array}$ \\
\hline
\end{tabular}

\begin{tabular}{|c|c|c|c|c|}
\hline \multirow{2}{*}{$\begin{array}{l}\text { NO. } \\
\text { NODE }\end{array}$} & FLOW & ELEVATION & HGL & $\begin{array}{l}\text { PRESSUR } \\
\mathrm{E}\end{array}$ \\
\hline & (LPS) & (M) & (M) & (M) \\
\hline 1 & $\overline{-}, 900$ & 1,00 & 24,78 & 23,78 \\
\hline 2 & $\overline{-}, 900$ & 1,00 & 21,02 & 20,02 \\
\hline 3 & $\overline{-}, 0,900$ & 1,00 & 20,82 & 19,82 \\
\hline 4 & $\overline{-}, 900$ & 1,00 & 19,94 & 18,94 \\
\hline 5 & 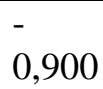 & 1,00 & 19,51 & 18,51 \\
\hline
\end{tabular}

\begin{tabular}{lll}
\hline 1 & 2013 & 5648 \\
2 & 2014 & 5699 \\
3 & 2015 & 5751 \\
4 & 2016 & 5802 \\
5 & 2017 & 5854 \\
6 & 2018 & 6907 \\
\hline
\end{tabular}

Sumber: hasil perhitungan

Tabel 7. Tekanan Air di titik simpul Hasil model progam loop 


\begin{tabular}{|c|c|c|c|c|}
\hline 6 & $\begin{array}{l}\overline{0} \\
0,900\end{array}$ & 1,00 & 19,28 & 18,28 \\
\hline 7 & $\begin{array}{l}- \\
0,900\end{array}$ & 1,00 & 17,36 & 16,36 \\
\hline 8 & $\begin{array}{l}- \\
0,900\end{array}$ & 1,00 & 20,26 & 19,26 \\
\hline 9 & $\begin{array}{l}- \\
0,900\end{array}$ & 1,00 & 19,66 & 18,66 \\
\hline 10 & $\begin{array}{l}- \\
0,900\end{array}$ & 1,00 & 19,34 & 18,34 \\
\hline 11 & $\begin{array}{l}- \\
0,900\end{array}$ & 1,00 & 20,15 & 19,15 \\
\hline 12 & $\begin{array}{l}- \\
0,900\end{array}$ & 1,00 & 19,86 & 18,86 \\
\hline 13 & $\begin{array}{l}- \\
0,900\end{array}$ & 1,00 & 19,81 & 18,81 \\
\hline 14 & $\begin{array}{l}- \\
0,900\end{array}$ & 1,00 & 19,51 & 18,51 \\
\hline 15 & $\begin{array}{l}- \\
0,900\end{array}$ & 1,00 & 19,64 & 18,64 \\
\hline 16 & $\begin{array}{l}- \\
0,900\end{array}$ & 1,00 & 19,19 & 18,19 \\
\hline 17 & $\begin{array}{l}- \\
0,900\end{array}$ & 1,00 & 19,34 & 18,34 \\
\hline 18 & $\begin{array}{l}- \\
0,900\end{array}$ & 1,00 & 19,25 & 18,25 \\
\hline 19 & $\begin{array}{l}- \\
0,900\end{array}$ & 1,00 & 18,90 & 17,90 \\
\hline 20 & $\begin{array}{l}- \\
0,900 \\
\end{array}$ & 1,00 & 18,48 & 17,48 \\
\hline 21 & $\begin{array}{l}- \\
0,900 \\
\end{array}$ & 1,00 & 18,78 & 17,78 \\
\hline 22 & $\begin{array}{l}- \\
0,900\end{array}$ & 1,00 & 18,98 & 17,98 \\
\hline 23 & $\begin{array}{l}- \\
0,900 \\
\end{array}$ & 1,00 & 18,94 & 17,94 \\
\hline 24 & $\begin{array}{l}- \\
0,900\end{array}$ & 1,00 & 18,71 & 17,71 \\
\hline 25 & $\begin{array}{l}- \\
0,900\end{array}$ & 1,00 & 18,83 & 17,83 \\
\hline 26 & $\begin{array}{l}- \\
0,900\end{array}$ & 1,00 & 18,59 & 17,59 \\
\hline 27 & $\begin{array}{l}- \\
0,900\end{array}$ & 1,00 & 18,54 & 17,54 \\
\hline 28 & $\begin{array}{l}- \\
0,900 \\
\end{array}$ & 1,00 & 18,58 & 17,58 \\
\hline 29 & $\begin{array}{l}- \\
0,900 \\
\end{array}$ & 1,00 & 18,33 & 17,33 \\
\hline 30 & $\begin{array}{l}- \\
0,900\end{array}$ & 1,00 & 18,33 & 17,33 \\
\hline 31 & $\begin{array}{l}- \\
0,900 \\
\end{array}$ & 1,00 & 18,44 & 17,44 \\
\hline 32 & $\begin{array}{l}- \\
0,900\end{array}$ & 1,00 & 17,94 & 16,94 \\
\hline
\end{tabular}

Sumber : Hasil perhitungan

\section{KESIMPULAN DAN SARAN}

Dari hasil kajian perencanaan pemenuhan air bersih di Desa Tambakrigadung dapat diambilkan beberapa kesimpulan, bahwa debit yang dibutuhkan di wilayah desa Tambakrigadung $\mathrm{Q}=10 \mathrm{l} / \mathrm{dtk}$. Dari hasil Analisa debit di Desa Tambakrigadung Dibutuhkan $\mathrm{Q}=10 \mathrm{l} / \mathrm{dtk}$. Sedangkan Debit yang ada di reservoir veteran $Q=30 \mathrm{l} / \mathrm{dtk}$ Untuk Perumahan Graha Indah membutuhkan Debit $\mathrm{Q}=4,63$ Jadi PDAM Lamongan dengan reservoir veteran bisa menyuplaiDesa Tambakrigadung pada 5 kedepan dengan pelayanan $80 \%$ dengan Q 10 l/dtk

\section{DAFTAR PUSTAKA}

Ali Masduqi, 2010, Keberlanjutan Sistem Penyediaan Air Bersih Perpipaan Di Perdesaan, Skripsi, Institut Teknologi Sepuluh Nopember, Surabaya

Dian Vitta Agustina, 2007, Analisa Kinerja Sistem Distribusi Air Bersih PDAM

Kecamatan Banyumanik Di Perumnas Banyumanik, Skripsi, Universitas Diponegoro, Semarang.

Djoko Sasongko, 1985 Teknik Sumber Daya Air, Jilid 1,

Dwingga Febriansyah, 2009, Evaluasi Sistem Distribusi Air Bersih Di Perumahan Graha Indah lamongan, Kabupaten Lamongan.

Guntur Mardieko Aji, 1999, Studi Evaluasi Sistem Jaringan Distribusi Air Bersih, Skripsi, Unisma, Malang.

Hartono, 2001, Perencanaan Pemenuhan kebutuhan Air Bersih, Skripsi, Unisma, Malang.

Sigit Setiyo Pramono, 2002, Pendekatan Sistem (system approach) Pada Pengelolaan Air Bersih Di Indonesia, Skripsi, Universitas Gunadarma, Jakarta 
